\title{
Pengaruh Kepuasan Kerja, Keterlibatan Kerja, dan Perceived Organizational Support Terhadap Komitmen Organisasional Pada Bank Syariah Mandiri
}

\author{
Aisyah Pia Asrunputri \\ Universitas Gadjah Mada, Indonesia \\ aisyahpia@yahoo.com
}

\begin{abstract}
ABSTRAK
Tujuan dari penelitian ini adalah untuk mengukur pengaruh kepuasan kerja, keterlibatan kerja, dan perceived organizational support terhadap komitmen organisasional pada Bank Syariah Mandiri kantor pusat di Jakarta. Yang menjadi latar belakang penelitian ini adalah dikarenakan adanya penurunan presentase dalam kenaikan nilai aset perbankan yang disebabkan oleh kurang berkomitmen dan kurangnya keterlibatan karyawan didalam organisasi. POS yang diberikan oleh Bank Syariah Mandiri kepada karyawan juga dinilai kurang mencukupi kebutuhan sosioemosional karyawan. Metode yang digunakan adalah kuantitatif yang memfokuskan pada 60 responden yakni karyawan di Bank Syariah Mandiri Kantor Pusat Jakarta. Berdasarkan temuan didalam penelitian ini membuktikan bahwa tidak ditemukannya hubungan positif antara kepuasan kerja dan komitmen organisasional serta POS dan komitmen organisasional. Namun ditemukan hubungan positif dan signifikan antara keterlibatan kerja dan komitmen organisasional.
\end{abstract}

Kata Kunci: kepuasan kerja, keterlibatan kerja, perceived organizational support, komitmen organisasional, bank syariah mandiri.

\section{Pendahuluan}

Perkembangan perbankan syariah di Indonesia bertumbuh pesat dengan dipayungi oleh Undang-Undang Nomor 21 Tahun 2008 tentang Perbankan Syariah yang dapat memicu peluang perbankan syariah untuk tumbuh dan maju serta untuk menciptakan permintaan akan produk dan pelayanannya untuk masyarakat Indonesia. Menurut Otoritas Jasa Keuangan (2015) pada tahun 2010 perbankan syariah di Indonesia memiiki aset mencapai 100 trilyun rupiah dan pada tahun 2014 meningkat menjadi 279 rupiah.

2. Tabel 1.1: Peningkatan Nilai Aset Perbankan Syariah Indonesia

\begin{tabular}{lccccc}
\hline & $\mathbf{2 0 1 0}$ & $\mathbf{2 0 1 1}$ & $\mathbf{2 0 1 2}$ & $\mathbf{2 0 1 3}$ & $\mathbf{2 0 1 4}$ \\
\hline $\begin{array}{l}\text { Bank Islam Komersial dan unit bisnis } \\
\text { yang lain }\end{array}$ & 97.5 & 145.5 & 195.0 & 242.3 & 272.3 \\
$\begin{array}{l}\text { Bank Islam Pedesaan } \\
\text { Total }\end{array}$ & 2.7 & 3.5 & 4.7 & 5.8 & 6.6 \\
Presentasi Kenaikan Nilai Aset & 100.3 & 149.0 & 199.7 & 248.1 & 278.9 \\
\hline
\end{tabular}

Sumber: Otoritas Jasa Keuangan 2015 
Meskipun terdapat peningkatan dalam aset perbankan syariah di Indonesia, telah terjadi penurunan presentase dalam kenaikan nilai aset tersebut. Pada tahun 2011 nilai aset perbankan syariah di Indonesia adalah sejumlah 49 persen, sedangkan pada tahun 2012 nilai aset tersebut berjumlah 34 persen. Begitu pula yang terjadi pada tahun 2013, presentase kenaikan hanya berjumlah 24 persen. Diikuti oleh tahun 2014, presentase kenaikan hanya berjumlah 12 persen. Penurunan presentase kenaikan nilai aset perbankan syariah disebabkan oleh semakin ketatnya persaingan di industri jasa keuangan. Selain itu juga dikarenakan oleh sumber daya manusia di perbankan syariah yang kurang kompeten dan inovatif (ASEAN Banking Integration Framework, 2016). Hal tersebut disebabkan, karyawan yang berkomitmen dan terlibat secara masif didalam komitmen organisasional akan menghasilkan hasil yang positif yaitu kompetensi dan inovasi (Matagi, 2003). Apabila, karyawan tersebut tidak berkomitmen dan terlibat secara aktif maka akan menghasilkan performa yang negatif pula.

Keterlibatan kerja sebagai variabel independen dalam hal ini berperan untuk menentukan tersedianya sumber daya manusia yang mampu berkomitmen dan terlibat secara aktif didalam organisasi (Edralin, 2008). Oleh karena itu, dengan adanya komitmen organisasional dan keterlibatan sumber daya manusia yang tinggi maka organisasi akan mampu untuk berinovasi dan mampu untuk bersaing dengan perbankan konvensional maupun lembaga keuangan lainnya. Didalam penelitian oleh Singh dan Gupta (2015) yang menjelaskan mengenai hubungan antara keterlibatan kerja, komitmen organisasional, komitmen tim dan komitmen profesional untuk mengeksplorasi perbedaan umum diantara variabel tersebut menilai bahwa keterlibatan kerja oleh karyawan dinilai sebagai tingkatan dimana seseorang secara psikologis berkomitmen atau tidak berkomitmen pada pekerjaannya. Karyawan yang memiliki keterlibatan kerja yang tinggi cenderung peduli terhadap pekerjaannya Dengan adanya keterlibatan kerja dan komitmen organisasional karyawan maka dapat meningkatkan kemajuan bagi organisasi.

Singh dan Gupta (2015) juga menjelaskan bahwa terdapat beberapa penelitian menunjukkan bahwa keterlibatan kerja memiliki hubungan positif dengan komitmen organisasional. Meski terdapat hubungan positif diantara keduanya, terdapat perbedaan yang signifikan antara keterlibatan kerja dengan komitmen organisasional yang mana keterlibatan kerja lebih cenderung pada identifikasi dari aktivitas pekerjaan. Sedangkan komitmen organisasional merupakan keterikatan seorang individu terhadap organisasinya. Oleh karena itu terdapat kasus dimana karyawan terlibat dengan pekerjaannya tetapi tidak berkomitmen pada organisasi atau sebaliknya. Studi oleh Wikaningrum (2011) yang menyelidiki mengenai kebijakan dan praktik sumber daya manusia dalam perbankan syariah menjelaskan bahwa karyawan yang terlibat namun tidak berkomitmen pada organisasi disebabkan karena organisasi kurang dapat memenuhi kebutuhan sosioemosional seperti afiliasi dan dukungan emosional untuk dapat menghasilkan sense of belonging yang kuat dari karyawan terhadap organisasi.

Sedangkan untuk kepuasan kerja juga merupakan hal yang esensial bagi performa organisasi. Berdasarkan studi oleh Gangai dan Agrawal (2014) mengenai hubungan antara kepuasan kerja dan komitmen organisasional dapat disimpulkan bahwa kepuasan kerja akan mempengaruhi banyak aspek dari pekerjaan seperti efisiensi, produktivitas, tingkat kehadiran, intensi keluar dan kesejahteraan karyawan. Performa dan kesuksesan organisasi itu sendiri ditentukan oleh karyawan, oleh karena itu karyawan yang puas akan pekerjaannya serta tempat ia bekerja, apabila diperlakukan dengan baik oleh organisasi akan mengarahkan pada konsekuensi yang 
positif seperti efektivitas, kinerja, produktivitas yang tinggi, dan rendahnya tingkat keluar masuknya karyawan. Karyawan yang memiliki kepuasan akan pekerjaannya akan setia dan berkomitmen pada pekerjaannya dan organisasi. Namun berdasarkan interview dengan salah satu karyawan Bank Syariah Mandiri yakni Bapak Aris menjelaskan mengenai tidak berkomitmennya beberapa karyawan dikarenakan tidak adanya kepuasan karir yang mereka dapatkan dari organisasi. Isi dari wawancara tersebut adalah sebagai berikut:

"Terdapat beberapa karyawan didalam Bank Syariah Mandiri tidak mendapatkan kepuasan dalam karir mereka. Hal ini dikarenakan oleh tidak adilnya gaji yang mereka dapatkan dengan kontribusi yang telah mereka berikan untuk organisasi. Hal ini dapat menjadi masalah dikemudian hari bagi Bank Syariah Mandiri karena dengan kurangnya komitmen dari karyawan dapat mempengaruhi performa dari Bank Syariah Mandiri."

Menurut organizational support theory, efektivitas perilaku karyawan yang dapat mempengaruhi performa organisasi ditentukan bagaimana persepsi karyawan ketika menerima perlakuan dari organisasi dan bagaimana organisasi dapat memenuhi kebutuhan sosio-emosional karyawan. Ketika hal itu terjadi dengan baik bagi karyawan, maka hubungan antara karyawan dengan organisasi akan memiliki kualitas yang baik. Dengan kualitas hubungan yang baik tersebut dapat menciptakan atmosfir yang mendukung karyawan untuk menjalankan aktivitas dan pekerjaannya didalam organisasi sehingga dapat menciptakan performa organisasi yang optimal. Dengan dukungan organisasional yang baik pula dapat memberikan arti dan tujuan bagi pengembangan diri karyawan tersebut. Dengan dukungan organisasional yang suportif dapat juga menjadi kunci dalam memperoleh komitmen organisasional dan juga meningkatkan efektivitas karyawan dalam bekerja. Namun, Menurut wawancara yang peneliti lakukan dengan Bapak Aris dari Bank Syariah Mandiri mengatakan sebaliknya. Isi wawancara tersebut adalah sebagai berikut: "Terdapat beberapa karyawan yang bekerja tidak optimal meskipun telah diberikan pelatihan-pelatihan untuk dapat meningkatkan komitmen, kompetensi dan produktivitas dari karyawan tersebut. Hal ini menyebabkan tujuan dari pelatihan tersebut tidak dapat terpenuhi."

Ayers (2010) didalam studinya menjelaskan bagaimana kepuasan kerja, keterlibatan kerja, dan perceived organizational support berperan sebagai prediktor dari komitmen organisasional. Yang menjadi latar belakang dari studi tersebut adalah dikarenakan adanya biaya yang tinggi untuk training dan supporting personel yang membuat organisasi meninjau ulang hubungan sensitive antara kepuasan kerja, keterlibatan kerja, dan perceived organizational support dan faktor-faktor lain yang terkait dengan komitmen organisasional. Studi oleh Ayers membuktikan bahwa kepuasan kerja, keterlibatan kerja, dan perceived organizational support membantu dalam membentuk perilaku karyawan terhadap organisasi salah satunya adalah komitmen organisasional dalam kontribusi karyawan terhadap kesuksesan organisasi.

Penelitian dari Suma dan Lesha (2013) yang meneliti mengenai tingkat kepuasan kerja dengan komitmen organisasional didalam sektor publik menunjukkan hubungan positif antara kepuasan kerja dan komitmen organisasional. Hal ini dikarenakan semakin puas karyawan, ia akan semakin berkomitmen dengan pekerjaannya. Penelitian dari Raymond dan Mjoli (2012) yang bertujuan untuk mengukur hubungan antara kepuasan kerja, keterlibatan kerja, dan komitmen organisasional antara lowerlevel employee pada industri yang berfokus pada pembuatan automobile menunjukkan bahwa kepuasan kerja memiliki hubungan yang lebih kuat dengan komitmen organisasional dibandingkan dengan keterlibatan kerja. Penelitian dari Ucar dan Otken (2010) yang bertujuan untuk mengukur hubungan antara perceived 
organizational support (POS) dan komitmen organisasional dengan organization based self-esteem sebagai moderating variable menunjukkan bahwa komitmen organisasional adalah salah satu dari konsekuensi dari POS. Karyawan yang memiliki POS yang tinggi akan merespon dengan sukarela terhadap organisasi dengan bentuk perilaku kerja yang positif, perilaku organisasional, dan juga dengan mendukung tujuan organisasi. Namun penelitian yang dilakukan oleh Onyinyi (2003) yang juga menginvestigasi hubungan antara komitmen organisasional dengan POS membuktikan bahwa POS memiliki hubungan yang lemah dengan komitmen organisasional namun signifikan. Dengan adanya perbedaan hasil penelitian tersebut diperlukan tatanan konsep yang perlu dilanjutkan.

\subsection{Perumusan Masalah}

Berdasarkan latar belakang diatas, rumusan masalah yang dapat diambil adalah sebagai berikut:

1. Sumber daya manusia yang kurang berkomitmen dan kurang terlibat didalam organisasi dapat menyebabkan perbankan syariah mengalami penurunan terhadap nilai asetnya.

2. POS (dukungan organisasi) seperti pelatihan-pelatihan yang diberikan di Bank Syariah Mandiri tidak cukup efektif dalam membantu karyawan untuk tetap berkomitmen tinggi dan produktif pada pekerjaannya di dalam organisasi. Disisi lain, POS (dukungan organisasi) dari perbankan syariah juga kurang mengoptimalkan hubungan dengan karyawan melalui pemenuhan kebutuhan sosio-emosional sehingga mengakibatkan karyawan kurang berkomitmen pada organisasi.

3. Kepuasan kerja yang rendah menjadi antecedent dari rendahnya komitmen organisasional di Bank Mandiri Syariah. Hal ini disebabkan oleh ketidakpuasan karyawan akan gaji yang diterima yang tidak sebanding dengan besarnya kontribusi yang telah diberikan kepada organisasi.

\subsection{Tujuan Penelitian}

Adapun tujuan dari penelitian ini berdasarkan identifikasi masalah tersebut diatas adalah sebagai berikut:

1. Menguji pengaruh kepuasan kerja terhadap komitmen organisasional di Bank Syariah Mandiri.

2. Menguji pengaruh keterlibatan kerja terhadap komitmen organisasional di Bank Syariah Mandiri.

3. Menguji pengaruh perceived organizational support terhadap komitmen organisasional di Bank Syariah Mandiri.

\subsection{Manfaat Penelitian}

Dengan dilaksanakannya penelitian diharapkan dapat berguna bagi beberapa pihak yaitu:

1. Untuk organisasi.

Hasil penelitian ini dapat digunakan sebagai bahan pertimbangan dalam proses pengambilan keputusan strategis atau kebijakan organisasi terutama mengenai bagaimana cara meningkatkan komitmen organisasional melalui peningkatan 
kepuasan kerja, keterlibatan kerja, dan perceived organizational support dari karyawan yang difasilitasi dan didukung oleh organisasi.

2. Untuk peneliti.

Penelitian ini dapat memperluas sekaligus memperkaya pengetahuan peneliti mengenai Manajemen Sumber Daya Manusia.

3. Untuk akademisi.

Penelitian ini bermanfaat untuk penelitian selanjutnya bagi akademisi.

4. Untuk masyarakat luas.

Penelitian ini dibuat khususnya untuk lingkungan perguruan tinggi serta mahasiswa didalamnya yang tertarik untuk memperkaya pengetahuan mengenai Sumber Daya Manusia dan pengetahuan terapan.

\section{Kajian teoritik}

\subsection{Kepuasan Kerja}

Terdapat banyak definisi dari konsep kepuasan kerja yang telah diformulasikan. Arnold dan Feldman (1986) didalam Roos (2005) menggambarkan kepuasan kerja sebagai "jumlah afeksi yang individu miliki terhadap pekerjaannya". Kepuasan kerja yang tinggi memiliki arti individu menyukai pekerjaannya, mengapresiasi dan memiliki perasaan positif mengenainya. McCormick dan Ilgen (1980) didalam Roos (2005) menjelaskan bahwa definisi yang mereka miliki serupa dengan yang dimiliki Arnold dan Feldman. Mereka juga menjelaskan bahwa kepuasan kerja adalah perilaku seseorang terhadap pekerjaannya dan menambahkan bahwa perilaku adalah respon emosional terhadap pekerjaan, yang mana berbeda secara kontinyu dari positif ke negatif.

2.2. Keterlibatan Kerja

Konsep keterlibatan kerja pertama dikembangkan oleh Lodahl dan Kejner pada tahun 1965 (Khan dan Nemati, 2011; Seng et al., 2012). Mereka mendefinifikan keterlibatan kerja sebagai tingkat dimana kepercayaan diri seseorang dipengaruhi oleh performa pekerjannya. Setelah itu, konsep ini dielaborasi lebih jauh oleh Kanungo (Ho, 2006; Seng et al., 2012). Ia mencoba untuk mengeliminasi ambiguitas mengenai konsep dari keterlibatan kerja dan menekankan kekurangan dari pengukuran yang terjadi pada pelitian terdahulu. Ia mendefinisikan keterlibatan kerja sebagai kepercayaan individu terhadap pekerjaannya dan ia juga mengatakan bahwa keterlibatan kerja berperan sebagai katalisator untuk memenuhi kebutuhan individu.

\subsection{Perceived Organizational Support (POS)}

Berdasarkan Eisenberger et al (1986) didalam Liu (2004), perceived organizational support atau POS didefinisikan sebagai persepsi karyawan mengenai tingkat kepedulian organisasi terhadap kesejahteraan dan bagaimana organisasi menghargai kontribusi mereka. POS merepresentasikan bagian yang penting dari hubungan pertukaran sosial antara karyawan dengan atasan karena POS mengimplikasikan apa yang organisasi telah berikan kepada karyawan menurut apa yang karyawan percayai.

\subsection{Komitmen Organisasional}

Komitmen organisasional menurut Porter (1974) didalam Mgulqwa (2008) didefinisikan sebagai kekuatan relative dari sebuah identifikasi individu dengan keterlibatannya didalam organisasi. Mowday, Steers dan Porter (1979) didalam 
Mgulqwa (2008) menambahkan bahwa komitmen organisasional terdiri atas 3 faktor yakni: 1) kepercayaan yang kuat dan penerimaan dari sebuah tujuan dan nilai organisasi, 2) kemauan untuk berupaya demi kepentingan organisasi, 3) hasrat yang kuat untuk menjaga keanggotaan dalam organisasi. O'Reilly (1987) didalam Mgulqwa (2008) mendefinisikan komitmen organisasional sebagai ikatan psikologis seorang individu dengan organisasinya termasuk rasa keterlibatan kerja, loyalitas, dan kepercayaan pada nilai-nilai organisasi. Komitmen organisasional dalam pandangan ini dikategorikan sebagai kesediaan seorang karyawan untuk menerima tujuan organisasi serta kemauan karyawan tersebut untuk berupaya untuk organisasi (Miller dan Lee, 2001; Mgulqwa, 2008).

\subsection{Hubungan Antar Variabel dan Perumusan Hipotesis}

\section{Hubungan Antara Kepuasan Kerja dan Komitmen Organisasional}

Berdasarkan Abebe dan Markos (2016) hubungan antara kepuasan kerja dan komitmen organisasional telah banyak ditemukan didalam literatur-literatur manajemen. Beberapa penelitian menemukan adanya hubungan positif antara kedua variabel tersebut. Feinstrein dan Vondrasek (2001) didalam Eslami dan Gharakhani (2012) menganalisa efek dari kepuasan kerja pada komitmen organisasional diantara karyawan restoran dan penemuan dari penelitian tersebut membuktikan bahwa tingkat kepuasan dapat memprediksi komitmen mereka pada organisasi. Eslami dan Gharakhani (2012) menguji peran dari kepuasan kerja pada komitmen organisasional yang mana hasilnya mengindikasikan bahwa kepuasan kerja memiliki efek positif dan signifikan dalam komitmen organisasional.

Sedangkan Suma dan Lesha (2013) didalam Abebe dan Markos (2016) melakukan penelitian untuk menentukan tingkat kepuasan dari karyawan pada sektor publik dengan dimensi pekerjaan dan POS di Shkoder, Albania. Suma dan Lesha mengeksplorasi tingkat komitmen karyawan terhadap pekerjaannya. Mereka menggunakan desain penelitian berdasarkan survey. Penemuan dari penelitian Suma dan Lesha mengindikasi bahwa kepuasan dan pekerjaan itu sendiri serta kualitas dari kepuasan supervisi memiliki pengaruh positif pada komitmen pekerjaan.

$\mathrm{H}_{1}$ : Kepuasan kerja memiliki pengaruh positif terhadap komitmen organisasional.

\section{Hubungan Antara Keterlibatan Kerja dan Komitmen Organisasional}

Keterlibatan kerja berperan didalam menentukan performa karyawan dan membentuk hasil organisasi. Sebagai contoh, penemuan dari Mowday et al (1979) didalam Almarshad (2015) mengindikasikan bahwa keterlibatan kerja memiliki dampak positif pada komitmen organisasional. Beberapa peneliti yang lain menunjukkan bahwa keterlibatan kerja memiliki hubungan yang signifikan dengan komitmen organisasional dan intensi keluar karyawan (Weissenberg, 1968; McElroy et al., 1999; Almarshad, 2015). Berdasarkan Cohen (1999) didalam Ho (2006), hubungan antara keterlibatan kerja dan komitmen organisasional berbasis pada teori pertukaran sosial dimana individu melakukan timbal balik kepada siapapun yang menguntungkan individu tersebut. Sehingga hubungan timbal balik terjadi di antara keterlibatan kerja, pengalaman kerja yang positif dan komitmen organisasional. Peran 
dari timbal balik karyawan ini didukung oleh Meyer et al (1998) didalam Ho (2006) ringkasan penelitiannya mengenai anteseden dari komitmen organisasional. Mereka menyimpulkan bahwa semakin tinggi tingkat komitmen afektif seseorang terhadap organisasi, semakin positif pengalaman kerja seseorang tersebut. Keterlibatan kerja merupakan karakteristik pribadi yang ditemukan berhubungan positif dengan komitmen organisasional (Stevens et al., 1978; Ho, 2006).

$\mathrm{H}_{2}$ : Keterlibatan kerja memiliki pengaruh positif terhadap komitmen organisasional.

\section{Hubungan Antara POS dan Komitmen Organisasional}

Hubungan antara POS dan komitmen organiasional secara umum dapat dijelaskan oleh asas timbal balik dan pertukaran sosial. Dari perspektif teori pertukaran sosial, Eisenberger et al (1986) didalam Ucar dan Otken (2010) berargumen bahwa kepercayaan yang mendasari kesimpulan karyawan mengenai komitmen organisasi kepada mereka berkontribusi pada komitmen karyawan kepada organisasi. Tingkat POS yang tinggi dapat menciptakan rasa tanggung jawab untuk karyawan. Karyawan akan merasa bertanggung jawab dan tidak hanya itu saja. Ia juga akan merasa wajib untuk membalas komitmennya kepada organisasi dengan memperlihatkan perilaku yang dapat mendukung tercapainya tujuan organisasi (Eisenberger et al, 1986; Ucar dan Otken, 2010). Karyawan yang berkomitmen secara efektif kepada organisasi dengan merasa bertanggung jawab untuk berkontribusi kepada kesejahteraan organisasi akan membantu organisasi untuk mencapai tujuannya. Karyawan kemudian membalas melalui komitmen afektif dan memperlihatkan upaya ekstra dalam pekerjaannya (Eisenberger et al, 1986; Ucar dan Otken, 2010). POS meningkatkan komitmen afektif dengan berkontribusi kepada kepuasan pemenuhan kebutuhan sosio-emosional karyawan seperti kepercayaan diri, persetujuan, dan afiliasi (Eisenberger et al, 1986; Fuller et al, 2003; Ucar dan Otken, 2010). Kepuasan ini akan berperan untuk meningkatkan identitas sosial karyawan dengan menjadikan karyawan sebagai anggota dari organisasi yang mana akan meningkatkan komitmen afektif dari karyawan (Ucar dan Otken, 2010).

$\mathrm{H}_{3}$ : POS memiliki pengaruh positif terhadap komitmen organisasional.

\section{Kerangka Pemikiran}

Berdasarkan uraian hubungan antar variabel diatas, maka kerangka penelitian dikemukakan sebagai berikut:

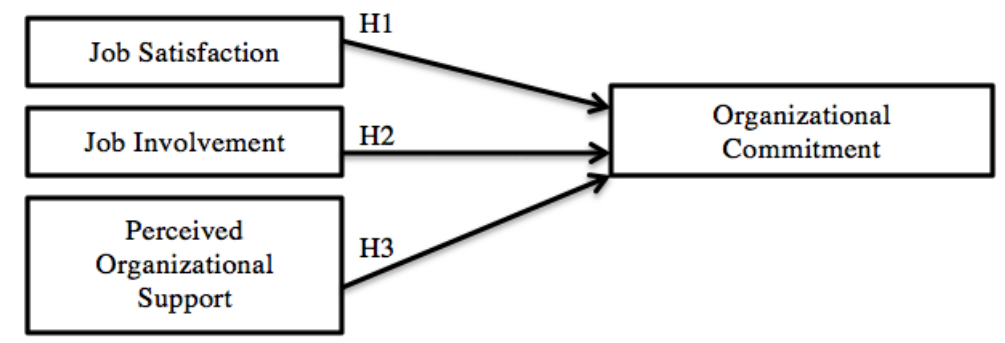




\section{Gambar 1.1 Kerangka Penelitian}

Sumber: Ayers 2010

Kerangka penelitian tersebut dibentuk berdasarkan replikasi model dalam penelitian yang dilakukan oleh Ayers (2010) dengan judul: Job Satisfaction, Job Involvement, and Perceived Organizational Support as Predictors of Organizational Commitment. Penelitian tersebut meneliti mengenai pengaruh kepuasan kerja, keterlibatan kerja, dan dukungan organisasi terhadap komitmen organisasional diantara para pendidik.

\section{Metode Penelitian}

Penelitian ini menggunakan pendekatan kuantitatif dengan pendekatan kualitatif sebagai penguat. Pendekatan ini akan dilakukan dengan pembagian kuesioner untuk menguji hipotesis yang telah dikembangkan serta menguji hubungan antar variabel dengan menggunakan software SPSS. Penelitian ini dilakukan untuk menguji pengaruh variabel independen yaitu pengaruh kepuasan kerja, keterlibatan kerja, dan perceived organizational support terhadap variabel dependen yakni komitmen organisasional. Adapun objek penelitian ini adalah Bank Syariah Mandiri. Populasi Bank Syariah Mandiri adalah 16.945 sedangkan sampel yang dipilih oleh peneliti didalam penelitian ini adalah sebanyak 60 responden.

\section{Hasil Dan Pembahasan}

5.1 Karakteristik Responden

Karakteristik dari 60 responden yang layak digunakan, disajikan pada tabel 1.2.

Tabel 1.2 Karakteristik Reponden

\begin{tabular}{|c|c|c|c|}
\hline Keterangan & & Jumlah & Persentase \\
\hline \multirow[t]{3}{*}{ Jenis Kelamin } & : (1) Laki-laki & 31 & 52.0 \\
\hline & (2) Perempuan & 29 & $\underline{48.0}$ \\
\hline & & 60 & 100 \\
\hline \multirow[t]{5}{*}{ Usia } & : (1) 20-29 & 11 & 18.0 \\
\hline & (2) $30-39$ & 38 & 64.0 \\
\hline & (3) $40-49$ & 7 & 12.0 \\
\hline & (4) 50 atau lebih & $\underline{4}$ & $\underline{6.0}$ \\
\hline & & 60 & 100 \\
\hline \multirow[t]{5}{*}{ Lama Bekerja } & $:(1)<2$ tahun & 17 & 28.0 \\
\hline & (2) 3-5 tahun & 30 & 50.0 \\
\hline & (3) 6-10 tahun & 11 & 18.0 \\
\hline & (4) $>16$ tahun & $\underline{2}$ & 4.0 \\
\hline & & 60 & 100 \\
\hline \multirow[t]{7}{*}{ Jabatan } & : (1) Kepala Bagian & 2 & 4.0 \\
\hline & (2) Kepala Seksi & 4 & 6.0 \\
\hline & (3) Team Leader & 4 & 6.0 \\
\hline & (4) Officer & 24 & 40.0 \\
\hline & (5) Pelaksana & 24 & 40.0 \\
\hline & (6) Lain-lain & $\underline{2}$ & $\underline{4.0}$ \\
\hline & & 60 & 100 \\
\hline
\end{tabular}




\begin{tabular}{|lc|c|c|}
\hline Pendidikan Terakhir & : (1) SMA & 2 & 4.0 \\
& (2) S1 & 53 & 88.0 \\
& (3) S2 & $\underline{5}$ & $\underline{\mathbf{8 . 0}}$ \\
\hline
\end{tabular}

\subsection{Pengujian Validitas dan Reliabilitas}

Uji Validitas

Uji Validitas Kepuasan Kerja

\begin{tabular}{|c|c|c|}
\hline Item & $\begin{array}{c}\text { Nilai Korelasi (Pearson } \\
\text { Correlation) }\end{array}$ & Kesimpulan \\
\hline Item 1 & 1 & Valid \\
\hline Item 2 & 0.482 & Valid \\
\hline Item 3 & 0.385 & Valid \\
\hline Item 4 & 0.404 & Valid \\
\hline Item 5 & 0.375 & Valid \\
\hline Item 6 & 0.401 & Valid \\
\hline Item 7 & 0.396 & Valid \\
\hline Item 8 & 0.508 & Valid \\
\hline
\end{tabular}

Sumber: Data Primer Diolah (2017)

Hasil uji validitas pada 8 item pertanyaan mengenai kepuasan kerja pada tabel diatas menunjukkan bahwa 8 item pertanyaan dinyatakan valid karena semua nilai korelasi $>$ nilai $\mathrm{r}$ table $(0.301)$. Dengan demikian 8 item pertanyaan mengenai kepuasan kerja akan digunakan untuk analisis data selanjutnya.

\section{Uji Validitas Keterlibatan Kerja}

\begin{tabular}{|c|c|c|}
\hline Item & $\begin{array}{c}\text { Nilai Korelasi (Pearson } \\
\text { Correlation) }\end{array}$ & Kesimpulan \\
\hline Item 1 & 0.688 & Valid \\
\hline Item 2 & 0.402 & Valid \\
\hline Item 3 & 0.820 & Valid \\
\hline Item 4 & 0.432 & Valid \\
\hline Item 5 & 0.661 & Valid \\
\hline Item 6 & 0.370 & Valid \\
\hline
\end{tabular}

Sumber: Data Primer Diolah (2017)

Hasil uji validitas pada 6 item pertanyaan mengenai keterlibatan kerja pada tabel diatas menunjukkan bahwa 6 item pertanyaan dinyatakan valid karena semua nilai korelasi $>$ nilai $\mathrm{r}$ table $(0.361)$. Dengan demikian 6 item pertanyaan mengenai keterlibatan kerja akan digunakan untuk analisis data selanjutnya. 
Uji Validitas Perceived Organizational Support

\begin{tabular}{|c|c|c|}
\hline Item & $\begin{array}{c}\text { Nilai Korelasi (Pearson } \\
\text { Correlation) }\end{array}$ & Kesimpulan \\
\hline Item 1 & 0.363 & Valid \\
\hline Item 2 & 0.362 & Valid \\
\hline Item 3 & 0.366 & Valid \\
\hline Item 4 & 0.380 & Valid \\
\hline Item 5 & 0.375 & Valid \\
\hline Item 6 & 0.532 & Valid \\
\hline Item 7 & 0.898 & Valid \\
\hline
\end{tabular}

Sumber: Data Primer Diolah (2017)

Hasil uji validitas pada 7 item pertanyaan mengenai perceived organizational support pada tabel diatas menunjukkan bahwa 7 item pertanyaan dinyatakan valid karena semua nilai korelasi $>$ nilai $\mathrm{r}$ table $(0.361)$. Dengan demikian 7 item pertanyaan mengenai perceived organizational support akan digunakan untuk analisis data selanjutnya.

\section{Uji Validitas Komitmen Organisasional}

\begin{tabular}{|c|c|c|}
\hline Item & $\begin{array}{c}\text { Nilai Korelasi (Pearson } \\
\text { Correlation) }\end{array}$ & Kesimpulan \\
\hline Item 1 & 0.369 & Valid \\
\hline Item 2 & 0.394 & Valid \\
\hline Item 3 & 0.550 & Valid \\
\hline Item 4 & 0.405 & Valid \\
\hline Item 5 & 0.378 & Valid \\
\hline Item 6 & 0.392 & Valid \\
\hline Item 7 & 0.454 & Valid \\
\hline Item 8 & 0.389 & Valid \\
\hline
\end{tabular}

Sumber: Data Primer Diolah (2017)

Hasil uji validitas pada 8 item pertanyaan mengenai komitmen organisasional pada tabel diatas menunjukkan bahwa 8 item pertanyaan dinyatakan valid karena semua nilai korelasi $>$ nilai $\mathrm{r}$ table (0.361). Dengan demikian 8 item pertanyaan mengenai komitmen organisasional akan digunakan untuk analisis data selanjutnya. 


\section{Uji Reliabilitas}

\begin{tabular}{|c|c|c|}
\hline Item & $\begin{array}{c}\text { Koefisien Cronbach's } \\
\text { Alpha }\end{array}$ & Keterangan \\
\hline Item 1 & 0.914 & Reliabel \\
\hline Item 2 & 0.919 & Reliabel \\
\hline Item 3 & 0.920 & Reliabel \\
\hline Item 4 & 0.918 & Reliabel \\
\hline Item 5 & 0.919 & Reliabel \\
\hline Item 6 & 0.920 & Reliabel \\
\hline Item 7 & 0.918 & Reliabel \\
\hline Item 8 & 0.918 & Reliabel \\
\hline Item 9 & 0.918 & Reliabel \\
\hline Item 10 & 0.915 & Reliabel \\
\hline Item 11 & 0.915 & Reliabel \\
\hline Item 12 & 0.915 & Reliabel \\
\hline Item 13 & 0.921 & Reliabel \\
\hline Item 14 & 0.926 & Reliabel \\
\hline Item 15 & 0.918 & Reliabel \\
\hline Item 16 & 0.922 & Reliabel \\
\hline Item 17 & 0.920 & Reliabel \\
\hline Item 18 & 0.919 & Reliabel \\
\hline Item 19 & 0.917 & Reliabel \\
\hline Item 20 & 0.914 & Reliabel \\
\hline Item 21 & 0.918 & Reliabel \\
\hline Item 22 & 0.922 & Reliabel \\
\hline Item 23 & 0.919 & Reliabel \\
\hline Item 24 & 0.919 & Reliabel \\
\hline Item 25 & 0.919 & Reliabel \\
\hline Item 26 & 0.919 & Reliabel \\
\hline Item 27 & 0.920 & Reliabel \\
\hline Item 28 & 0.919 & Reliabel \\
\hline Item 29 & 0.925 & Reliabel \\
\hline
\end{tabular}

Setelah kuesioner telah berhasil melewati uji validitas kemudian uji reliabilitas dilakukan. Uji reliabilitas ini dilakukan untuk menguji konsitensi alat ukur. Uji reliabilitas ini menggunakan Cronbach's Alpha dimana semakin nilai mendekati 1,0 maka nilai tersebut semakin baik (Sekaran, 2010). Tabel diatas menunjukkan bahwa seluruh variabel memiliki nilai diatas 0,361 sehingga dapat disimpulkan bahwa seluruh variabel dalam penelitian ini reliabel.

\subsection{Pengujian Hipotesis dan Pembahasan}

Hipotesis 1 menyatakan bahwa kepuasan kerja berpengaruh terhadap komitmen organisasional. Hasil pengolahan data menunjukkan koefisien regresi hubungan antara kepuasan kerja dengan komitmen organisasional sebesar 0.710 . Dikarenakan nilai koefisien regresi diatas 0.05 maka hipotesis 1 tidak terpenuhi. Hasil ini menjelaskan bahwa kepuasan kerja yang dirasakan oleh karyawan Bank Syariah Mandiri tidak memiliki pengaruh yang berarti untuk mendorong mereka untuk berkomitmen pada organisasi. Studi oleh Markowitz et. al. (2010) juga membuktikan bahwa tidak adanya hubungan positif antara kepuasan kerja dan komitmen organisasional terutama terkait dengan kepuasan ekstrinsik dan komitmen kontinyuan. Menurut Maskowitz et. al. (2010), kepuasan ekstrinsik dan kepuasan intrinsic secara 
lebih kuat berhubungan dengan komitmen afektif dan normatif terkait dengan karyawan di sektor publik dibandingkan dengan karyawan di sektor swasta.

Hipotesis 2 menyatakan bahwa keterlibatan kerja berpengaruh terhadap komitmen organisasional. Hasil pengolahan data menunjukkan bahwa koefisien regresi hubungan antara keterlibatan kerja dan komitmen organisasional sebesar 0.039. Dikarenakan nilai koefisien regresi dibawah 0.05 maka hipotesis 2 terpenuhi. Penelitian ini didukung dengan adanya penelitian oleh Kaplan et.al. (2012) mengenai hubungan antara kepuasan kerja dan komitmen organisasional. Dalam studinya Kaplan et.al. (2012) menjelaskan bahwa terdapat hubungan positif antara kepuasan kerja dan komitmen normatif.

Hipotesis 3 menyatakan bahwa POS berpengaruh terhadap komitmen organisasional. Hasil pengolahan data menunjukkan bahwa koefisien regresi hubungan antara POS dengan komitmen organisasional sebesar 0.059. Dikarenakan nilai koefisien regresi diatas 0.05 maka hipotesis 3 tidak terpenuhi. Penelitian ini didukung oleh penelitian oleh Rhoades dan Eisenberger (2001) juga menemukan hubungan antara POS dan komitmen kontinyuan. Begitu pula penelitian oleh Aube et.al. (2007) yang menunjukkan adanya perbedaan kebijakan mengenai kesejahteraan karyawan di sektor publik dan sektor swasta. Menurut Aube et. al. (2007), dokter di sektor publik lebih khawatir mengenai nasib pekerjaannya dibandingkan dengan dokter yang bekerja di sektor swasta. Hal ini dikarenakan mereka tidak memiliki cukup pilihan atau alternatif bekerja ditempat lain. Namun meskipun mereka memiliki alternatif yang cukup, mereka akan tetap merasa terjebak didalam organisasi mereka.

\section{Kesimpulan Dan Saran}

Berdasarkan analisis yang telah dilakukan oleh peneliti dapat disimpulkan bahwa kepuasan kerja tidak memiliki pengaruh positif terhadap komitmen organisasional. Temuan dari penelitian ini menjelaskan bahwa karyawan di Bank Syariah Mandiri tidak memiliki kepuasan kerja serta komitmen organisasional yang tinggi. Selanjutnya, berdasarkan temuan didalam penelitian ini, peneliti menemukan hubungan positif antara keterlibatan kerja dan komitmen. Hal ini juga didukung oleh jurnal-jurnal terdahulu mengenai hubungan antara keterlibatan kerja dan komitmen.

Oleh karena itu, semakin tinggi tingkat tingkat keterlibatan kerja maka akan semakin tinggi pula komitmen organisasi karyawan di Bank Syariah Mandiri. Temuan terakhir adalah mengenai hubungan antara POS dan komitmen organisasional. Didalam penelitian ini tidak ditemukan hubungan positif antara POS dengan komitmen organisasional. Hal ini menurut Aube et. al. (2007) dikarenakan kebijakan di sektor publik tidak cukup memperhatikan kesejahteraan karyawannya dibandingkan dengan kebijakan di sektor swasta. Oleh karena itu karyawan di sektor publik memiliki tingkat POS yang rendah dibandingkan dengan karyawan yang bekerja di sektor swasta dengan demikian komitmen organisasional karyawan pun menjadi rendha.

Temuan penelitian ini memberikan implikasi praktis bagi pimpinan Bank Syariah mandiri . Karena keterlibatan kerja menjadi variabel yang menentukan komitmen organisasional. Oleh karena itu Bank Syariah Mandiri disarankan untuk memberikan perhatian terhadap karyawan yang memfokuskan pada keterlibatan kerja seperti dengan job enrichment dan job rotation ataupun mereka ulang job content dari karyawan sehingga karyawan akan lebih tertantang dan bersemangat sehingga semakin terlibat dalam menjalani pekerjaan didalam organisasi sehingga dapat berkontribusi pada produktivitas organisasi dengan lebih masif. Bank Syariah Mandiri 
juga dapat menggelar seminar yang menarik bagi karyawan untuk menambah pengetahuan dan memperkaya kemampuan perbankan dari karyawan.

\section{Daftar Pustaka}

Abebe, T. dan Markos, S. (2016). "The Relationship Between Job Satisfaction and Organizational Commitment in Public Higher Education Institution: The Case of Arba Minch University, Ethiopia”. Impact Journal Vol 4, pp. 19-24.

Almarshad, S., O. (2015). "Quality of Work Life and Organizational Commitment in Saudi Arabia: The Role of Job Involvement and Sense of Efficacy”. European Journal of Business and Social Sciences Vol. 4 No. 2, pp. 141-142.

Anttila, E. (2014). Components of Organizational Commitment. Master Thesis. University of Tampere.

Armstrong, M. (2012). A Handbook of Human Resource Management Practice. Kogan Page Limited: London.

Ayers, J., P. (2010). Job Satisfaction, Job Involvement and Perceived Organizational Support as Predictors of Organizational Commitment. Doctoral Dissertation. Walden University.

Aziri, B. (2011). "Job Satisfaction: A Literature Review". Management Research and Practice Vol. 3, pp. 77-85.

Bank Syariah Mandiri (2017). Laporan Tahunan 2016.

Behestifar, M. (2012). 'Effect Perceived Organizational Support on Employees' Attitudes Toward Work". Science Series Data Report Vol. 4, No. 9, pp. 3032.

Bobek, V. (2015). Perspectives on Business and Management. InTech: Austria.

Boxall, P. (2011). Strategy and Human Resource Management. Palgrave Macmillan: New York.

Chakrabarty, K., C. (2012) Human Resource Management in Banks - Need for a New Perspective. Press Release. Bank for International Settlements.

Chin, Y., Y. The Antecedents of Organizational Commitment in Banking Industry. Master Thesis. Universiti Tunku Abdul Rahman.

Ekmekci, A.,K. (2011). "A Study on Involvement and Commitment of Employees in Turkey". Journal of Public Administration and Policy Research Vol. 3 No. 3, pp. 68-69.

Fitriani, RMR. (2014). Bab 1: Pendahuluan. Master Thesis. Universitas Muhammadiyah Surakarta.

Gangai, K., N. dan Agrawal, R. (2015). "Job Satisfaction and Organizational Commitment: Is It Important for Employee Performance". International Journal of Management and Business Research Vol. 5 No. 4, pp. 271-272.

Global Business Guide Indonesia (2015) Islamic Banking in Indonesia - A Giant Waking Up.

Hasanah, N. (2014). Pengaruh Keterlibatan Kerja Terhadap Kepuasan Kerja Karyawan Ditjen Penyelenggara Haji dan Umrah Kementrian Agama Republik Indonesia (KEMENAG RI). Bachelor Thesis. Universitas Islam Negeri Syarif Hidayatullah.

Hidayat, W. (2016). Uji Normalitas. Modul Perkuliahan. Universitas Siliwangi.

Ho, C., C. (2006). A Study of The Relationships Between Work Values, Job Involvement and Organizational Commitment Among Taiwanese Nurses. Doctoral Dissertation. Queensland University of Technology. 
Hosseini, M. dan Nia, H., T. (2015). "Correlation between Organizational Commitment and Job Involvement of Physical Education Teachers of Schools of Zanjan”. International Journal of Basic Sciences and Applied Research. Vol. 4, pp. 7-8.

Ibrahim, R., M. dan Salleh, M. (2014). "The Link Between Leader-Member Exchange, Organizational Citizenship Behavior and Job Satisfaction: A Case Study on Local Government". International Journal of Academic Research in Business and Social Sciences Vol. 4 No. 5, pp. 315.

Imam, A., Raza, A. dan Ahmed, M. (2014). "Impact of Job Satisfaction on Organizational Commitment in Banking Sector Employees in Pakistan". Science International Vol. 26 No. 1, pp. 420.

Infobanknews.com (2016) Tantangan Perbankan Syariah di 2016.

Ismail, N. (2012). Organizational Commitment and Job Satisfaction Among Staff of Higher Learning Education Institutions in Kelantan. Master Thesis. University Utara Malaysia.

Karanges, E., Beatson, A., Johnston, K. dan Lings, I. (2016). "Optimizing employee engagement with internal communication: A social exchange perspective". International Journal of Humanities and Management Sciences, Vol. 4, pp. 195-197.

Karim, F. dan Rehman, O. (2012) "Impact of Job Satisfaction, Perceived Organizational Justice and Employee Empowerment on Organizational Commitment in Semi-Government Organizations of Pakistan". Journal of Business Studies Quarterly Vol. 3 No. 4, pp. 93-94.

Klein, H., J., Becker, T., J., dan Meyer, J., P. (2009). Commitment in Organizations: Accumulated Wisdom and New Directions. Routledge: New York.

Kumar, D. dan Sharma, M. (2013). "Human Resource Management". International Journal of Innovative Research in Technology, pp. 60-62.

Kusmarjanti, U. dan Soetjipto, H., P. (2007). "Dukungan Organisasi dan Komitmen Organisasi”. Jurnal Kebijakan dan Administrasi Publik, Vol. 11 No. 1, pp. 3037.

Leow, K., L. dan Khong, K.,W. (2009). “Organizational Commitment: The Study of Organizational Justice and Leader Member Exchange (LMX) Among Auditors in Malaysia". Knowledge Taiwan Vol. 4 No. 2 , pp. 168-170.

Liu, W. (2004). Perceived Organizational Support: Linking Human Resource Management Practices With Important Work Outcomes. Doctoral Dissertation. University of Maryland.

Loganathan, R. (2013) The Influence of Leadership Styles On Job Satisfaction At a Cellulose Pulp Mill in Kwazulu-Natal: A Case Study. Master Thesis. Durban University of Technology.

Love, K. (2005). Generational Impacts on Organizational Commitment: An examination of the Baby Boom Generation and Generation X at work. Master Thesis. Carleton University.

Luddy, N. (2005). Job Satisfaction Amongst Employees At a Public Health Institution in the Western Cape. Master Thesis. University of the Western Cape.

Malik, M, E., Nawab, S., Naeem, B. dan Danish, R.,Q. (2010). "Job Satisfaction and Organizational Commitment of University Teachers in Public Sector of Pakistan". International Journal of Business and Management, Vol. 5 No. 6, pp. 18-20. 
Matagi, L. (2012). Competency, Work Attitudes and Performance of Sub-County Chiefs in the Ugandan Government. Doctoral Dissertation. Makerere University.

Mathis, R., L., Jackson, J., dan Valentine, S., R. (2011). Human Resource Management. Cengage Learning: Stamford.

Matondang, Z. (2009). "Validitas dan Reliabilitas Suatu Instrumen Penelitian". Journal Tabularasa PPS Unimed, Vol. 6 No. 1, pp. 89-93.

Mguqulwa, N. (2008). The Relationship Between Organisational Commitment And Work Performance in an Agricultural Company. Master Thesis. University of South Africa.

Mohamed, L., K. dan El-Shaer, A., M. (2013) "Professional Commitment and Perceived Organizational Support Among Nursing Academic Staff: A Comparative Study". Medical Journal of Cairo University, Vol. 81, No. 1, pp. 240.

Mummedy, P., K. (2008). The Impact of Perceived Organizational Support on Innovativeness of Entry-Level Employees Working in the Information Technology Sector of Hyderabad, India. Master Thesis. University Sains Malaysia.

Noe, R., Hollenbeck, J., Gerhart, B., dan Wright., P. (2004). Fundamentals of Human Resource Management. McGraw-Hill Education: New York.

Ntisa, A., A. (2015). Job Satisfaction, Organizational Commitment, Turnover Intention, Absenteeism, and Work Performance Amongst Academics Within South African Universities. Doctoral Dissertation. Vaal University of Technology.

Nwibere, B., M. (2014). "Interactive Relationship Between Job Involvement, Job Satisfaction, Organizational Citizenship Behavior, and Organizational Commitment in Nigerian Universities". International Journal of Management and Sustaibility, Vol. 3 No. 6, pp. 324-326.

Oz, E., U., Derekoylu, T., Buyukbay, S., S. dan Yildiz, D. (2013). "What Has Job Satisfaction Got To Do With Employee Commitment? A Research Study on LMX and Work Attitudes". Journal of Global Strategic Management, Vol. 7 No. 1, pp. 80-81.

Pamungkas, W., S. (2013). Uji Asumsi Klasik. Modul Perkuliahan. Universitas Muhammadiyah Yogyakarta.

Pamungkas, W., S. (2013) Uji Statistik Deskriptif. Modul Perkuliahan. Universitas Muhammadiyah Yogyakarta.

Prasetio, A., P., Yuniarsih, T. dan Ahman, E. (2017). "Job Satisfaction, Organizational Commitment, Organizational Citizenship Behavior in Stateowned Banking". Universal Journal of Management Vol. 5 No. 1, pp. 34.

PricewaterhouseCoopers (2014). "Indonesian Banking Survey 2014". Pp. 21.

Rahati, A., Arani, H., S., Hajbaghery, M., A., dan Rostami, M. Job Involvement and Organizational Commitment of Employees of Prehospital Emergency Medical System. Nursing and Midwifery Studies, pp. 2.

Rasouli, R. dan Haghtaali, M. (2009) "Impact of Leader-Member Exchange on Job Satisfaction in Tehran Social Security Branches". Journal of Public Administration Institute for Turkey and Middle East, pp. 9-10.

Rizwan, M. (2011). "Relationship of Job Involvement With Employee Performance: Moderating Role of Attitude". Research Gate, pp. 81-82.

Robbins, S., P. (2014). Organizational Behavior. Pearson Education Limited: Harlow. 
Roos, W. (2005). The Relationship Between Employee Motivation, Job Satisfaction And Corporate Culture. Master Thesis. University of South Africa.

Saari, L., M. dan Judge, T., A. (2004). "Employee Attitudes and Job Satisfaction". Wiley Periodicals, Inc. pp. 398-399.

Seppanen, A., M. (2012) Perceptions of Perceived Organizational Support and Affective Organizational Commitment in Radisson Blu Seaside. Master Thesis. University of Applied Sciences.

Singh, A. dan Gupta, B. (2015). Job Involvement, Organizational Commitment, Professional Commitment and Team Commitment: A Study of Generational Diversity. Research Gate.

Singla, R., K. Principles of Management. (2015). VK Global Publication: New Delhi.

Sowmya, K., R. dan Panchanatham, N. (2011). "Factors Influencing Job Satisfaction of Banking Sector Employees in Chennai, India". Journal of Law and Conflict Resolution Vol. 3 pp. 77-78.

Sanusi, S., R. (2014). Beberapa Uji Validitas dan Reliabilitas Pada Instrumen Penelitian. University of Sumatera Utara Institutional Repository, pp. 113114.

Satardien, M. (2014) Perceived Organizational Support, Organizational Commitment and Turnover Intentions Amongst Employees in a Selected Company in the Aviation Industry. Master Thesis. University of the Western Cape.

Saxena, S. dan Saxena, R. (2015). "Impact of Job Involvement and Organizational Commitment on Organizational Citizenship Behavior". International Journal of Business and Management Research, Vol. 5 No. 1, pp. 19-20.

Seng, G., C., Xin, H., W., dan Chin, T., Y. (2012). Factors Affecting Employees' Job Involvement in Fast Food Industry. Bachelor Thesis. University of Tunku Abdul Rahman.

Shodganga. (2013). Chapter III: The Relevance of Organizational Commitment. Shodganga, pp. 50-54.

Singh, R. (2013). "Human Resouce Management in the Indian Banking Sector". Journal of Human Resource and Sustainability Studies Vol. 1, pp. 25-26.

Suma, S. dan Lesha, J. (2013) "Job Satisfaction and Organizational Commitment: The Case of Shkodra Municipality". European Scientific Journal, Vol. 9 No. 17, pp. 42-46.

Sya'ban, A. (2005) Teknik Analisis Data Penelitian: Aplikasi Program SPSS dan Teknik Menghitungnya. Diklat. Universitas Muhammadiyah Prof. Dr. Hamka.

Ulfa, N. dan Anis, N. (2017). "Pengaruh Kecerdasan Emosional Terhadap Keterlibatan Kerja dan Komitmen Organisasional Dengan Persepsi Politik Organisasi Sebagai Variabel Moderasi Pada Karyawan PT. PLN (PERSERO) AREA Banda Aceh”. Jurnal Universitas Syiah Kuala, pp. 4-7.

Ulrich, D. Human Resource Champions. (1997). Harvard Business School Press: United States of America.

Tayyar, K., A. (2014). Job Satisfaction and Motivation Amongst Secondary School Teachers in Saudi Arabia. Doctoral Dissertation. University of York.

Tolentino, R., C. (2013) "Organizational Commitment and Job Performance of the Academic and Administrative Personnel". International Journal of Information Technology and Business Management, Vol. 15 No. 1, pp. 56.

Tumwesigye, G. (2010). "The Relationship Between Perceived Organizational Support and Turnover Intentions in a Developing Country: The Mediating Role of Organizational Commitment". Journal of Business Management Vol. 4 No. 6, pp. 943-944. 
Ucar, D. dan Otken, A., B. (2010). "Perceived Organizational Support and Organizational Commitment: The Mediating Role of Organization Based SelfEsteem". Academic Research Index, pp. 88-90.

Ulfah, M. (2011) Modul Perkuliahan Psikometri. Universitas Mercubuana.

Universitas Sumatera Utara (2011). Bab II: Landasan Teori. Master Thesis. Universitas Sumatera Utara.

Universitas Udayana (2011). Bab II: Kajian Pustaka dan Hipotesis. Master Thesis. Universitas Udayana.

Unutmaz, S. (2014). Factors Affecting Job Satisfaction of Employees in a Public Institution. Master Thesis. Middle East Technical University.

Wikaningrum, T. (2011). "Praktek dan Kebijakan Manajemen Sumber Daya Manusia Pada Perbankan Syariah". Jurnal Siasat Bisnis, Vol. 15 No. 1, pp 100-120.

Yojana, Y. (2011). Analisis Pengaruh Pengelolaan SDM Terhadap Komitmen Keroganisasian Dengan Dukungan Organisasi Sebagai Variabel Antara Di Badan PPSDM Kesehatan, Kementrian Kesehatan RI. Master Thesis. Universitas Indonesia. 